\title{
Investigation of Hurricane Katrina characteristics for future, warmer climates
}

\author{
Barry H. Lynn ${ }^{1}$, Richard Healy ${ }^{2}$, Leonard M. Druyan ${ }^{2, *}$ \\ ${ }^{1}$ Department of Earth Sciences, Hebrew University of Jerusalem and Weather-It-Is, Ltd., Efrat, Israel \\ ${ }^{2}$ Center for Climate Systems Research, Columbia University and NASA Goddard Institute for Space Studies, 2880 Broadway, \\ New York, New York 10025, USA
}

\begin{abstract}
Simulations of Hurricane Katrina using the Weather Research and Forecasting (WRF) model on a $9 \mathrm{~km}$ grid over the Gulf of Mexico and the southeast United States are analyzed. Global Forecast System (GFS) analyses provided the initial fields and lateral boundary conditions (LBC) 4 times per day to drive a control simulation during the period 27 to 30 August 2005. The control captured many of the observed characteristics of Katrina. A new approach, mean signal nesting, was devised to make climate change projections of the storm for each decade in the 21st century. Mean climate change signals were extracted from A2 scenario projections of the future climate by an atmosphere-ocean global climate model (AOGCM). These signals were combined with the GFS data used in the control to create the initial fields and LBC for WRF climate change simulations. This innovative method allows the LBC to retain realistic sub-daily variability present in GFS data, but still include the climate change signal. Hurricane simulations representing the earlier decades tracked east of the 2005 trajectory, and west of that track for 4 of the 5 later decades. Sensitivity experiments suggest that anticipated atmospheric warming versus expected positive sea surface temperature trends have opposing influences on developing storms. Warming trends during the 21st century are associated with ever-increasing vertical thermal stability, inhibiting initial hurricane intensification and limiting their diameters. Eye wall wind speeds in excess of $60 \mathrm{~m} \mathrm{~s}^{-1}$ at the time of landfall could be sustained for a somewhat longer duration in storms toward the end of the 21st century.
\end{abstract}

KEY WORDS: Climate change $\cdot$ Hurricanes $\cdot$ Weather Research Forecasting regional model $\cdot$ WRF Resale or republication not permitted without written consent of the publisher

\section{INTRODUCTION}

Hurricane Katrina, which reached category 5 on the Saffir-Simpson scale on 28 August 2005, caused widespread devastation mainly to the coastal areas of Louisiana and Mississippi. Pielke et al. (2008) estimate that hurricane-related damages in the United States for 2004-2005 alone exceeded \$150 billion. They also determined that some $85 \%$ of normalized hurricane property damages in the USA since 1900 is accounted for by category 3,4 and 5 storms. In this context, the influence of long-term climate change on the behavior of Katrina-like storms has obvious importance. This study seeks to evaluate this influence.
Regional climate models (RCMs) have been used to downscale global climate model (GCM) output in order to better focus on the spatial details of regional climate change (e.g. Giorgi et al. 1994, Nobre et al. 2001, Han \& Roads 2004, Leung et al. 2004, Lynn et al. 2007). Ideally, RCMs can improve the representation of local meteorology for climate change impact studies because they employ higher grid resolution than GCMs, and also more effectively resolve convective-scale processes, topographically driven circulations and air-sea contrasts leading to sea-breeze circulations (Giorgi \& Marinucci 1996, Mass et al. 2002, Leung et al. 2003).

One interesting problem for dynamic downscaling is to predict the future behavior of a well developed hurricane within regimes of anticipated global warming. 
A skillful, high resolution, nested RCM can reasonably represent the storm's dynamics, while the future environment in which the storm is embedded could be estimated from GCM simulations forced by prescribed positive trends in atmospheric concentrations of greenhouse gases. Emanuel et al. (2008) used Intergovernmental Panel on Climate Change (IPCC) GCM simulations (scenario A1B) downscaled by independent track models to project future tropical storm paths, and a separate coupled air-sea model to predict future hurricane intensities. Their study gives projections of the climatology of tropical storm characteristics for the last 20 yr of the 22nd century. Shen et al. (2000) used a triply nested hurricane model on an inner $18 \mathrm{~km}$ grid to investigate the relative impacts of sea surface temperature (SST) changes and vertical thermal stability on hurricane intensity. Knutson et al. (2007) used an $18 \mathrm{~km}$ grid RCM nested within National Center for Environmental Prediction (NCEP) reanalysis to investigate recent trends of Atlantic hurricane activity.

However, there is evidence that RCM simulations nested within GCM-generated climate data are often compromised by unrealistic characteristics of the driving GCM (Rojas \& Seth 2003, Misra \& Kanamitsu 2004). Lynn et al. (2009) found that Mesoscale Model version 5 (MM5) simulations running over the USA and driven by NCEP reanalysis generated a more realistic frequency of heavy vs. light precipitation events than when driven by the Goddard Institute for Space Studies (GISS) atmosphere-ocean GCM (AOGCM). They postulated that this was because reanalysis provided more realistic daily variability in the synoptic fields than the AOGCM. This presents a great challenge for regional climate studies that use GCM projections for downscaling climate change due to anthropogenic forcing.

The problem is especially acute in the present study, which aims to simulate the short-term variability of a Hurricane Katrina-type storm, since important meteorological forcing cannot be supplied by the coarse-grid AOGCM. To address this deficiency, we used a new method - mean-signal nesting — which strives to overcome some of the limitations of GCM inadequacies by creating more suitable initial and lateral boundary conditions (LBC) for driving the Weather Research and Forecasting (WRF) model. Misra \& Kanamitsu (2004) improved initial conditions and LBC from a GCM by replacing GCM climatology with reanalysis climatology, while preserving the GCM's short-term variability. Their approach was suitable for correcting against model drift, thereby improving RCM seasonal forecasts. However, such an approach cannot be used for a 5 day simulation of hurricane development, where the sub-daily variability of the boundary conditions is crucial. Moreover, there is need here to account for cli- mate change due to anthropogenic forcings. Hence, in the present study, AOGCM projections of future climate are combined with realistic $4 \times$ per day variability taken from August 2005 NOAA NCEP Global Forecast System (GFS) analysis data on a $1 \times 1^{\circ}$ grid. More specifically, in mean-signal nesting, a mean climate change signal (CCS) representing decadal climate evolution is derived from AOGCM projections and combined with the GFS to create initial conditions and LBC for driving WRF simulations. This approach is offered here as an alternative to exclusive AOGCM forcing. Just as mesoscale models can be driven with unadjusted GFS to downscale the current climate, the new approach uses the (adjusted) analysis data combined with the CCS as LBC for WRF simulations that project future climate scenarios. Details of the meansignal nesting method are given in the next section.

The present study aims to determine the hypothetical effect that global climate change would have on a storm similar to Hurricane Katrina in the Gulf of Mexico (in 2005). Results are offered at $10 \mathrm{yr}$ intervals until the end of the 21st century.

\section{EXPERIMENTAL DESIGN}

The simulations of Katrina characteristics were made with version 2.1 of WRF (Skamarock et al. 2005) run over a limited area. The WRF domain includes the Gulf of Mexico, southeast USA and the adjacent North Atlantic Ocean $\left(19-39^{\circ} \mathrm{N}, 75-95^{\circ} \mathrm{W}\right)$. WRF horizontal grid spacing was $9 \mathrm{~km}$ and the model was integrated at 31 vertical levels. All simulations cover the period 27 to 31 August. The $9 \mathrm{~km}$ grid spacing was considered a suitable compromise between resolution requirements and computational efficiency for the stated domain. However, WRF computed grid point wind speeds and the implied convergence are underestimated compared to tracking data. In addition, the experiments use prescribed SST rather than an interactive ocean. The consequence of this limitation on results is unknown. WRF simulations were forced by data derived from the A2 climate change scenario defined by the IPCC (2007) as simulated by the GISS AOGCM (Russell et al. 1995, Rangwala et al. 2006). The AOGCM uses a $4 \times 5^{\circ}$ horizontal grid at 9 vertical atmospheric levels and 13 vertical ocean levels. Projections of future storm behavior in the present study therefore reflect the biases of the GISS AOGCM.

A control WRF simulation of Hurricane Katrina was initialized at 00:00 h UT on 27 August 2005 and continued through 31 August. Initial conditions and lateral boundary forcing data for this simulation were taken from the GFS archive. In addition, WRF simulations of Hurricane Katrina were forced by the LBC obtained 
using mean-signal nesting based on the AOGCM A2 scenario results for every decade from 2010-2019 until the 2090s, as follows.

The mean-signal nesting approach began with the calculation of a decadal mean annual cycle for each variable, computed as $10 \mathrm{yr}$ averages of the 6-hourly ( $4 \times$ per day) AOGCM output from the A2 scenario simulation. These decadal averages were then temporally smoothed by calculating $90 \mathrm{~d}$ running means, which effectively contain the signal of decadal seasonal means. The decadal $90 \mathrm{~d}$ running means of geopotential height, temperature, wind components and relative humidity were thus computed from the AOGCM output for both the base period (2000 to 2009) and for each subsequent decade of the 21st century. The resulting temporally smoothed annual cycle for each variable in the 2000s data set was then subtracted from its counterpart in each future decade. This difference represents the annual cycle of a CCS for each $6 \mathrm{~h}$ period during the year. The CCS of each variable was then added to corresponding variables of $4 \times$ per day GFS for 27 to 31 August 2005 to produce LBC for the WRF climate projection runs. This procedure was followed for each individual decade. Since the CCS is based on AOGCM climate projections for 10 consecutive summers, it is more representative of the A2 scenario forcing than any individual summer would be. Note that geostrophic and hydrostatic balances between temperature and circulation fields in the WRF simulations are not compromised because the adjustments to the LBC are derived at spatially large scales (on the $4 \times 5^{\circ}$ grid), and then the spatially smooth signal is applied to the GFS data on the $1 \times 1^{\circ}$ grid. The addition of the CCS to the weather variability signal of the 2005 GFS data therefore produces a dynamically balanced data set of 'future' conditions. WRF climate change simulations used AOGCM decadal mean SST from the A2 scenario simulation.

The advantage of this new approach is that the $4 \times$ per day variability of GFS analyses is retained in the CCS-adjusted LBC. These LBCs, in turn, supply the sub-daily variability in the initial and boundary conditions necessary to spin up a hurricane, while accounting for the potential climate change impacts on such hurricanes. This is an improvement over downscaling AOGCM coarse resolution simulations, which have unrealistic features and supply no high-resolution information particularly relevant for hurricane development.

Eight additional simulations with the same boundary forcing were created and evaluated for the WRF control case and the WRF projections for the 2090s. Section 3.3 discusses the variability of storm behavior attributable to slightly altered initial conditions on 27 August.

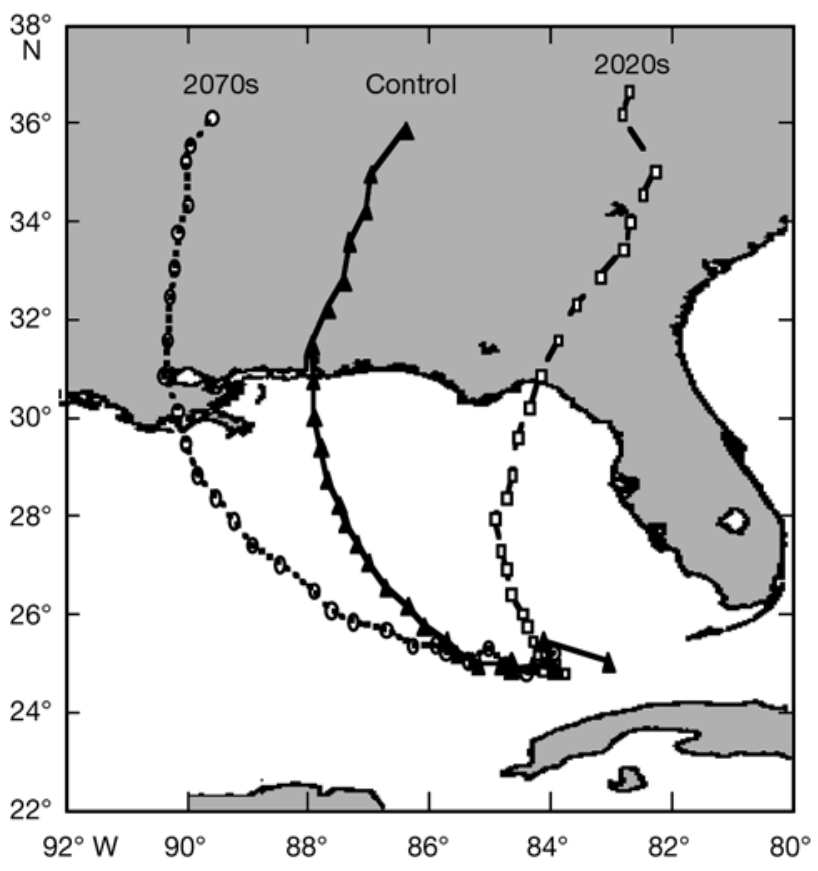

Fig. 1. Three Weather Research and Forecasting (WRF) simulated tracks of Hurricane Katrina. Positions are given at $3 \mathrm{~h}$ intervals

\section{RESULTS}

\subsection{Storm tracks}

Fig. 1 shows WRF storm tracks based on the locations of minimum sea-level pressure every $3 \mathrm{~h}$. For clarity, only 3 tracks are shown. The track labeled control (CTL) represents the results of the simulation initialized and forced with August 2005 GFS data. The CTL track makes landfall at $87.9^{\circ} \mathrm{W}$ (after $60 \mathrm{~h}$ ), which is only about $1.5^{\circ}$ longitude east of the observed trajectory of Hurricane Katrina. The track for the 2050s was close to the CTL track, while tracks for the next 4 decades were more westerly, bracketed by the track for the 2070s shown in Fig. 1, for which landfall occurred at $90.0^{\circ} \mathrm{W}$ (after $54 \mathrm{~h}$ ). The tracks for the earlier decades were all more easterly, bracketed by the track shown for the 2020s (Fig. 1), which crossed the coastline at $84.6^{\circ} \mathrm{W}$ (after $53 \mathrm{~h}$ ). The track for the 2090s was almost as easterly as the one shown for the 2020s and made landfall over the Florida panhandle (at $\left.85.2^{\circ} \mathrm{W}\right)$ after only about $48 \mathrm{~h}(00: 00 \mathrm{~h}$ UT 29 August), some $12 \mathrm{~h}$ before the CTL. In fact, many of the storm characteristics in the 2090s simulation were markedly different from results obtained for the 2050s through 2080s. The anomalous behavior of the storm for the 2090s simulation is given special attention in the conclusions section.

Fig. 2 compares the horizontal distribution of surface wind speed of the 2070s and 2080s simulations to the 

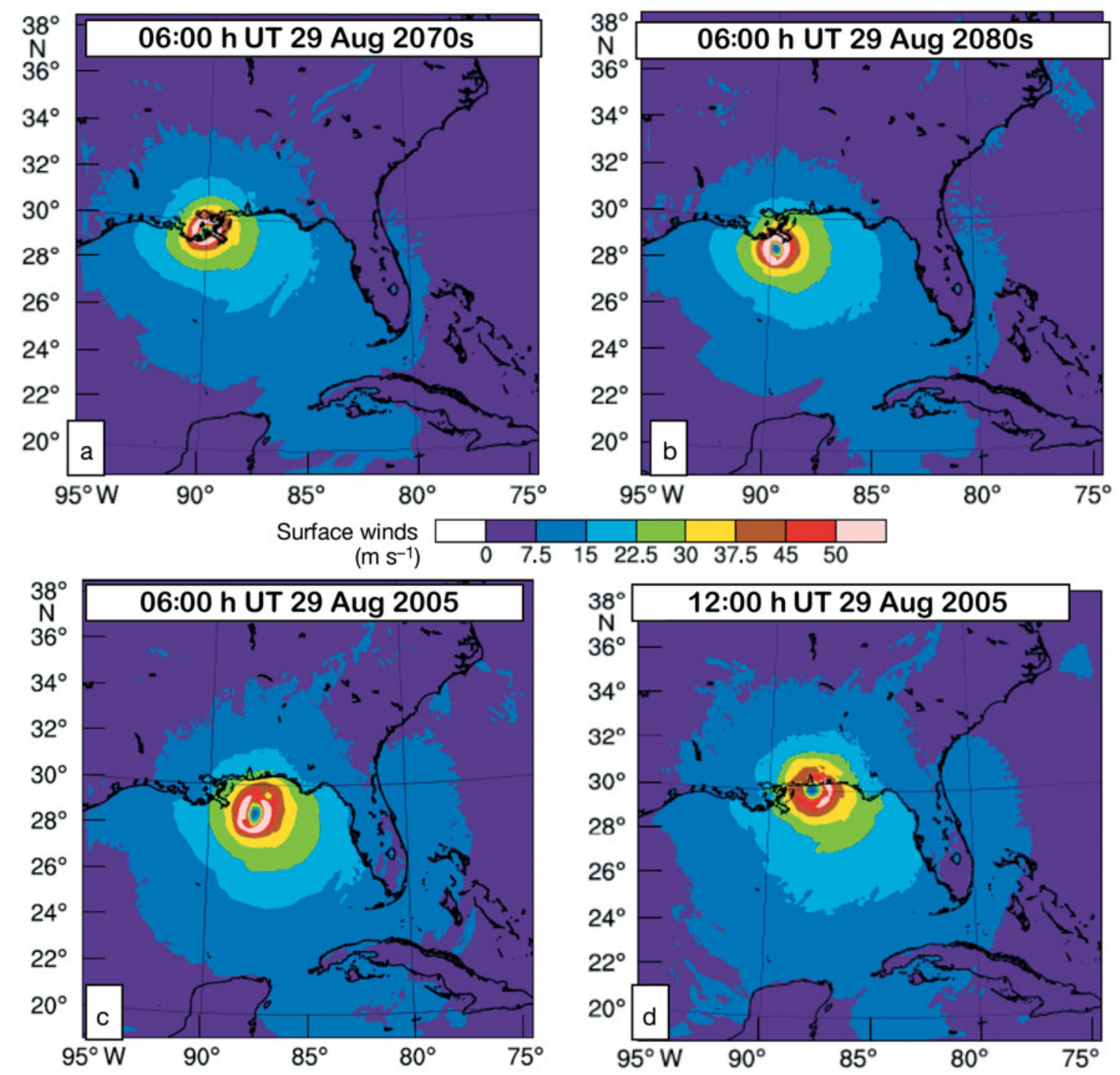

Fig. 2. Modeled (Weather Research and Forecasting model) surface wind speed (a) 2070s, (b) 2080s, (c,d) control simulations. All model runs were after $54 \mathrm{~h}$, except (d), which was after $60 \mathrm{~h}$

CTL after $54 \mathrm{~h}$ (06:00 h UT on August 29). After $54 \mathrm{~h}$ of elapsed time, the 2070s storm center (Fig. 2a) crosses the Louisiana coastline at $90^{\circ} \mathrm{W}$, the 2080 s storm center (Fig. 2b) is within $100 \mathrm{~km}$ to the southeast, while the CTL storm (Fig. 2c) is displaced further east. The CTL center makes landfall some $6 \mathrm{~h}$ later (Fig. 2d). The 2070s and 2080s storms appear to be somewhat more compact. For example, the diameter within which their wind speeds exceed $30 \mathrm{~m} \mathrm{~s}^{-1}$ is about $20 \%$ smaller than for the CTL (2.9 versus $\left.3.6^{\circ}\right)$. Nevertheless, the future storms seem to maintain their core of very high winds better than the CTL as they approach the coast. Fig. 2a,b depicts narrow rings of wind speeds $>50 \mathrm{~m} \mathrm{~s}^{-1}$. Compared to the CTL at landfall (Fig. 2d), the 2070s and 2080s storms feature a more compact core of high winds, but unlike the CTL, their respective bands of wind speed exceeding $50 \mathrm{~m} \mathrm{~s}^{-1}$ completely surround the storm center.

Fig. 3 shows vertical profiles of the simulated zonal wind anomaly relative to CTL values at 00:00 h UT on August 27. The anomaly profiles were spatially averaged over an area bounded by $20-30^{\circ} \mathrm{N}, 80-95^{\circ} \mathrm{W}$. Profiles for simulations representing the earlier decades and the 2090s show a large positive vertical shear relative to the CTL, reaching maxima between approximately 12 and $16 \mathrm{~km}$ altitude. Profiles from the latter decades show a negative anomaly shear up to about 8 to $10 \mathrm{~km}$ altitude. This is consistent with the differences in tracks discussed above. Stronger midtropospheric westerlies in the initial conditions representing each of the first 4 decades (and the 2090s) steered the evolving storm on a more easterly course 


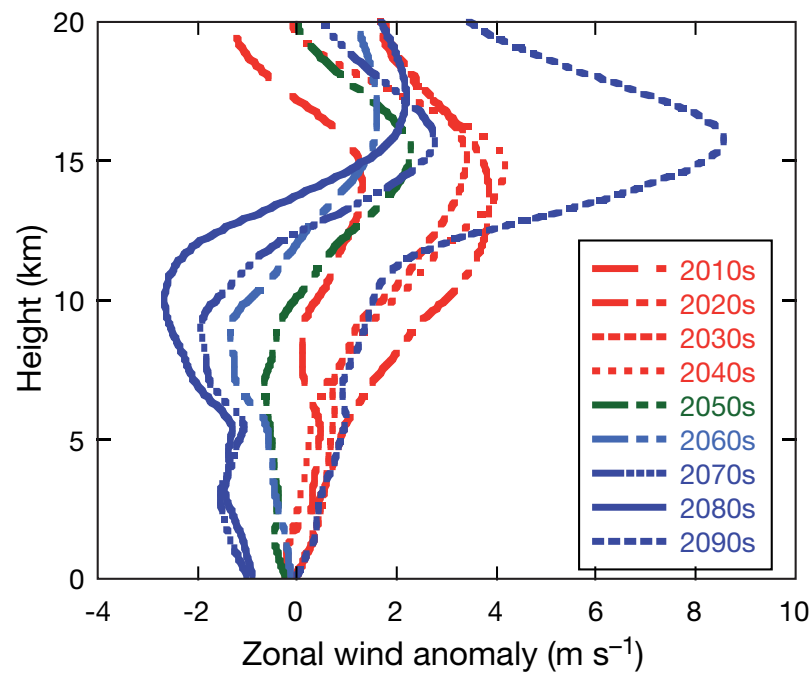

Fig. 3. Vertical profiles of zonal wind anomaly for each decadal simulation at 00:00 h UT 27 August. Anomalies are relative to the control run and are averaged over the area $20-30^{\circ} \mathrm{N}, 80-95^{\circ} \mathrm{W}$

than during the 2050s through the 2080s, which experienced weaker zonal steering currents.

The vertical shear of the zonal wind is proportional to north-south temperature gradients. The negative shear in the simulations representing the 2050s through the 2080s indicates a weakening or a reversal of the usual south to north temperature gradient. This can occur when the continent north of the Gulf of Mexico becomes excessively warm compared to the water temperature. NCEP reanalysis long-term (1968 to 1996) August mean skin temperature ranges from about $30^{\circ} \mathrm{C}$ over the Gulf to about $26^{\circ} \mathrm{C}$ over the Lower Mississippi Valley. This gradient ultimately drives the westerlies aloft. One result of decadal warming will be a differential warming of the continents relative to the oceans. The effect will be to weaken westerly steering currents along the Gulf coast, thereby allowing tropical storms to drift further westward than would be consistent with the current climate.

An example of the above scenario can be demonstrated by examining actual anomalies for a recent summer. Fig. 4a shows the August 2007 anomaly of skin temperature from NCEP reanalysis data. Note the skin temperature anomalies exceeding $2 \mathrm{~K}$ over the Lower Mississippi Valley, in contrast to near zero or slightly positive anomalies in Gulf of Mexico SST. This weakening of the south to north temperature gradient in turn weakened the westerly vertical wind shear within the lower troposphere, resulting in $700 \mathrm{mb}$ zonal wind anomalies along the Gulf coast $<-2 \mathrm{~m} \mathrm{~s}^{-1}$ (Fig. 4b). It is also worth noting that stronger zonal winds aloft along the Gulf Coast are associated with El Niño years.
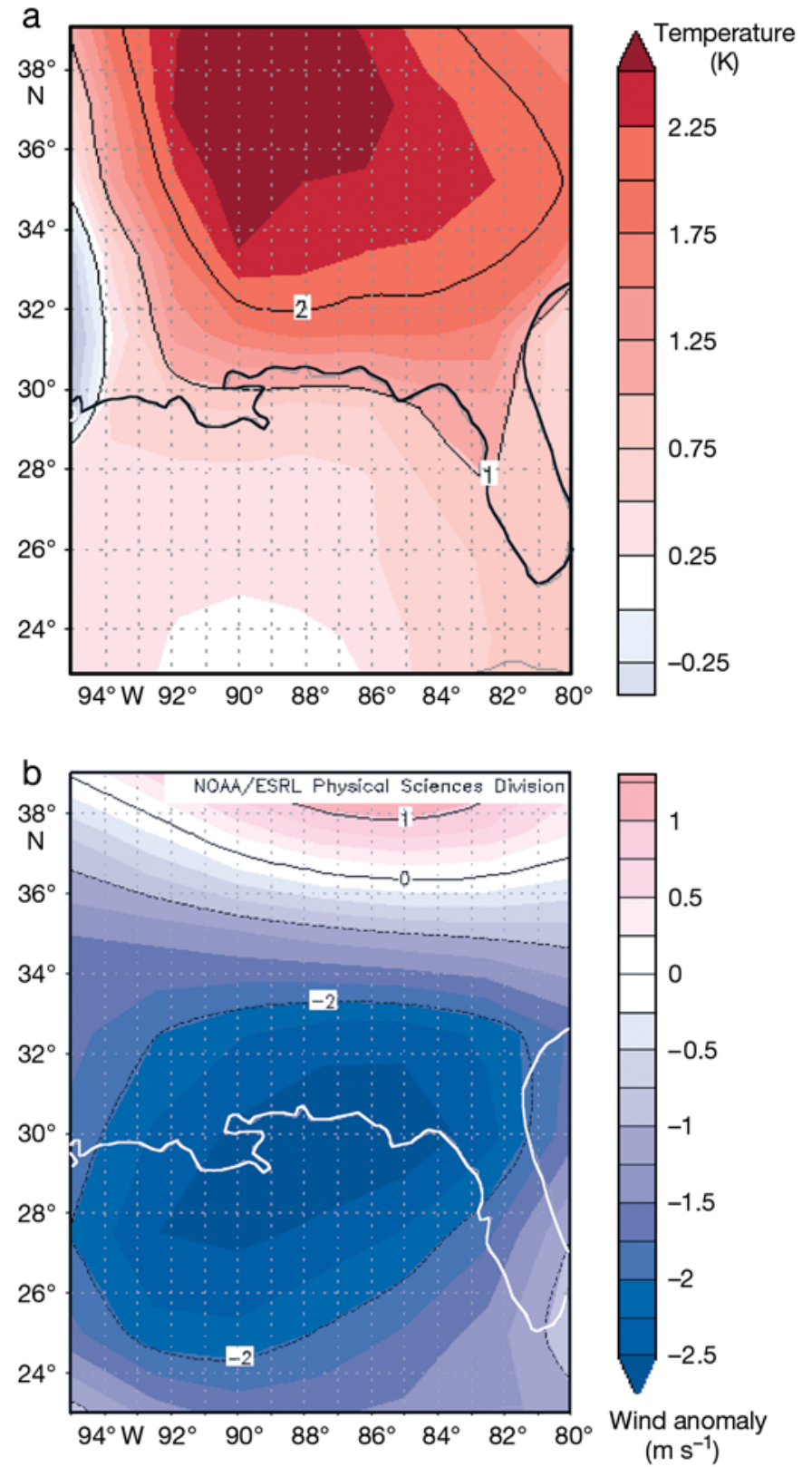

Fig. 4. National Center for Environmental Prediction (NCEP) reanalysis 1 August 2007 means for (a) SST and ground temperature anomalies and (b) $700 \mathrm{mb}$ zonal wind anomalies, both relative to 1968-1996 means (courtesy NOAA/Earth System Research Lab)

\subsection{Evolution of storm characteristics}

Fig. 5 shows the time evolution of simulated central (minimum) pressure for the CTL and the simulations representing the projected climate for each decade. Note that it takes about $10 \mathrm{~h}$ of WRF integration on the $9 \mathrm{~km}$ grid for minimum pressures to decrease to values comparable to those obtained from NOAA tracking, probably because surface pressures were initialized 


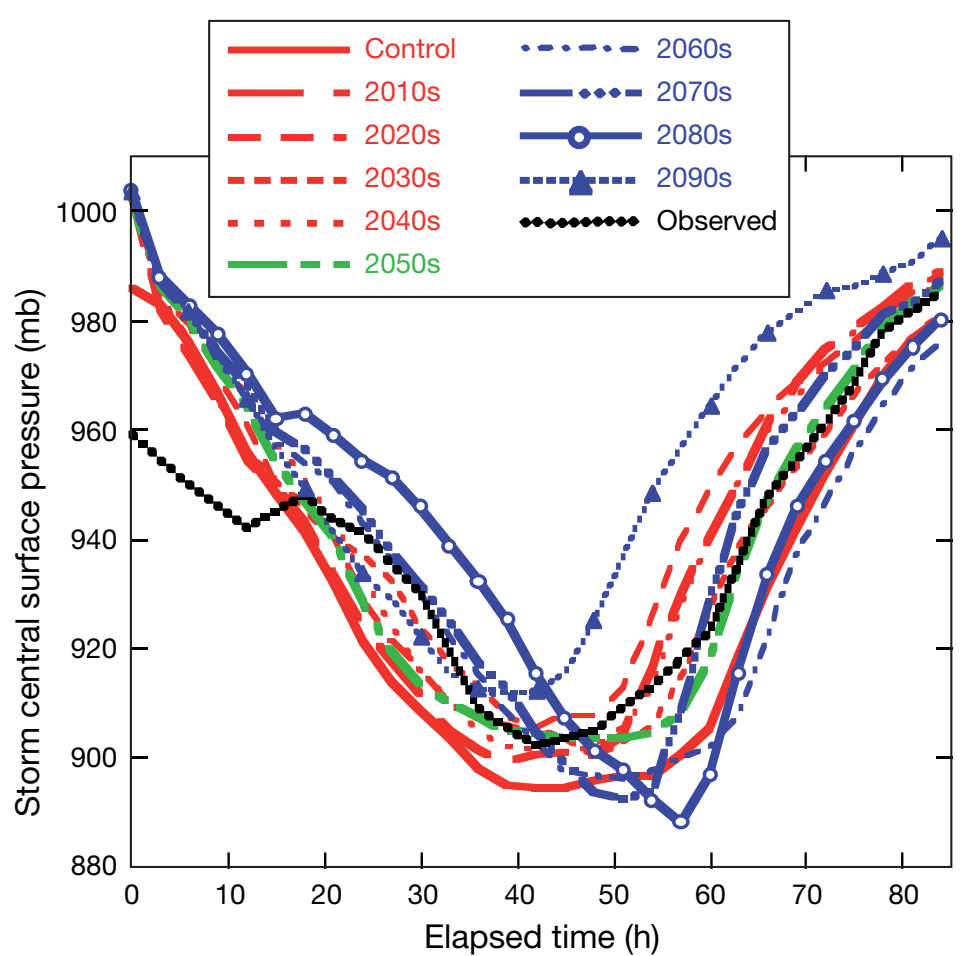

Fig. 5. Time series of minimum surface pressure for the control simulation and each decadal simulation. Observed values refer to NOAA tracking data

from GFS $1^{\circ}$ grid data. The WRF CTL exaggerates the deepening central pressure by about $5 \mathrm{mb}$, but the timing is reasonable, reaching a minimum value of $895 \mathrm{mb}$ after $45 \mathrm{~h}$ of elapsed time. The simulations for the 2050s through the 2080s delay the deepening by 10 to $20 \mathrm{~h}$ compared to the CTL, while the representations of earlier decades show evolutions of minimum surface pressure more similar to the CTL. As in the case of storm track and zonal wind profile, the time evolution of minimum surface pressure for the 2090s simulation is both anomalous and also closer to results from the earlier decades. The simulations for the 2070 s and 2080 s realized the most extreme minimum pressures (888 and $892 \mathrm{mb}$, respectively). The association of the more westerly tracks with delayed deepening and extreme central pressure can perhaps be partially explained by the distribution of SST in the Gulf of Mexico. Climatological August mean SSTs (NCEP reanalysis August 1968 to 1996) are approximately $1 \mathrm{~K}$ higher along the projected 2070s track (shown in Fig. 1) than along the 2020s track. The delay in reaching the minimum pressure and the more extreme deepening in the simulations representing the latter decades is perhaps related to their more westerly trajectories, which allow longer storm residence time over warmer ocean water than the storms representing earlier decades. In addition, stronger positive vertical wind shear weakens tropical storm development, and this is consistent with the shallower central pressures for the simulations representing the 2010s through the 2040s.

Fig. 6 shows the mean SST within $180 \mathrm{~km}$ of the storm center, averaged over all twenty-nine $3 \mathrm{~h}$ interval positions for each decadal run, the CTL and the minimum storm central surface pressure in each case. The general warming trend of SST throughout the century is evident, although with several qualifications. The SSTs under the storm were coolest for the 2020s, not for the CTL or the 2010s as might be expected. The increases in minimum pressure between the CTL and the 2020s are probably a consequence of atmospheric conditions becoming less favorable for hurricane development during the first 2 decades, accompanied by a slight decrease in SST. SSTs are highest for the 2080s, and only second highest for the 2090s. Minimum storm central pressures for decadal simulations decrease with increasing SST between the 2050s through the 2080s, with the most extreme of both values associated with the 2080s storm. The rather shallow minimum storm central pressure for the 2090s does not fit this general pattern. Shen et al. (2000) and Knutson \& Tuleya (2004) also found a general deepening of simulated hurricane central pressure with increasing lower boundary SST.

Time series of the maximum surface wind speed at $3 \mathrm{~h}$ intervals (data not shown) do not provide any clear picture of decadal variability. Owing to the limits of the model and the finite resolution of model results, simu-

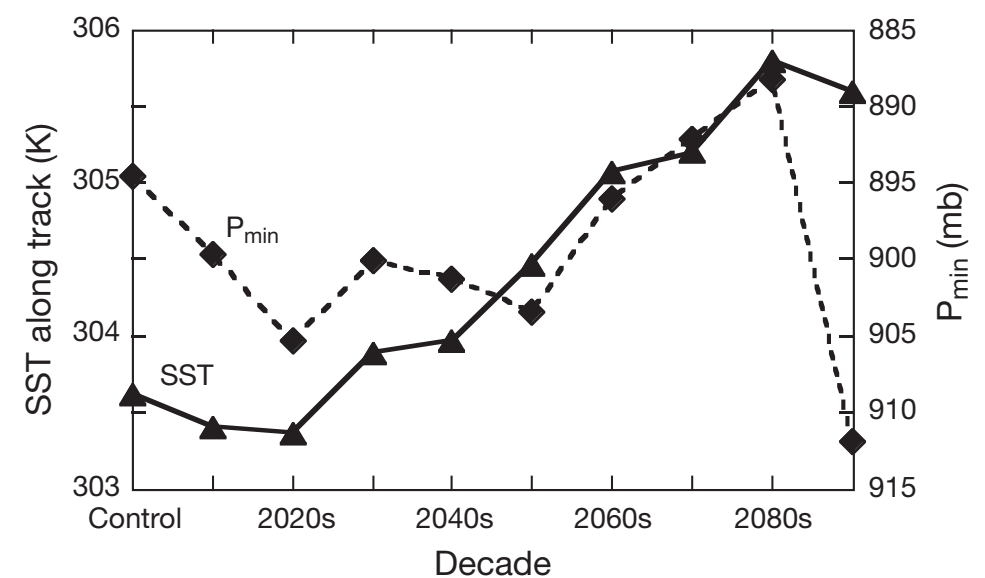

Fig. 6. Area-averaged sea surface temperature (SST, K) (or land skin temperature) within $180 \mathrm{~km}$ of storm center averaged over twenty-nine $3 \mathrm{~h}$ interval positions, and minimum storm surface pressure $\left(\mathrm{P}_{\min }\right)$, versus decade 


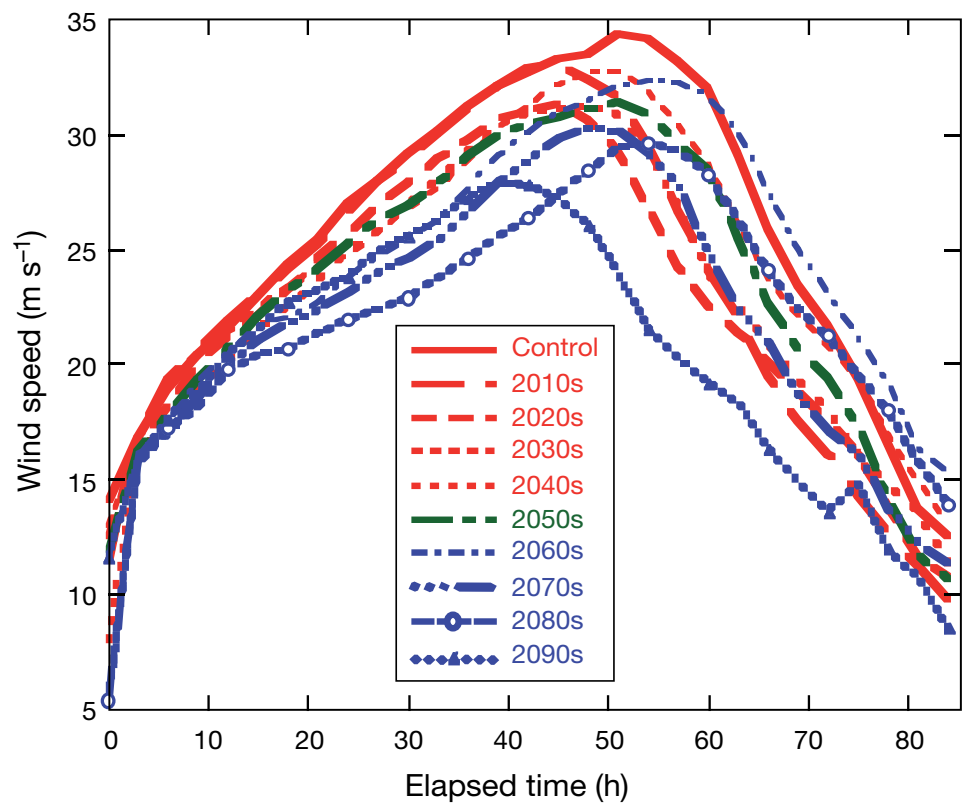

Fig. 7. Time series of area-averaged surface wind speed within $180 \mathrm{~km}$ of storm center

lated CTL wind speed maxima were some $20 \mathrm{~m} \mathrm{~s}^{-1}$ weaker than the NOAA tracking values at the height of the storm. Fig. 7 shows the area-averaged surface wind speed within a circular radius of $180 \mathrm{~km}$ of the storm center, at $3 \mathrm{~h}$ intervals. In general, the area-averaged wind speed peaks close to the time of minimum central pressure. Thus, wind speeds associated with the simulated storm representing the 2090s peak after only $39 \mathrm{~h}$, compared to the storms simulated for the other decades, which featured peak speeds as late as $54 \mathrm{~h}$. The strongest area-averaged wind speeds correspond to the CTL and the weakest to the 2070s through the 2090s. This implies that climate change toward the end of the 21st century will make areaaveraged wind speeds associated with Katrina-like storms weaker by perhaps $5 \mathrm{~m} \mathrm{~s}^{-1}$ compared with 2005 conditions.

The impact of hurricanes on populations is of course of great interest. In an effort to assess the differential impacts of a future Katrina on populations, Fig. 8 plots, for each decadal simulation, time series of maximum surface wind speeds over any land point in the domain for each $3 \mathrm{~h}$ record. The peak CTL speed over land, about $66 \mathrm{~m} \mathrm{~s}^{-1}$, occurs after $60 \mathrm{~h}$ elapsed time, at about the time of landfall (Fig. 2). Only one other simulation (for the 2060s) reached its overland peak later than $60 \mathrm{~h}$, while another registered a higher overland maximum speed: $67 \mathrm{~m} \mathrm{~s}^{-1}$ for the 2070s. Note that overland wind speed maxima in $>60 \mathrm{~m} \mathrm{~s}^{-1}$ occurred earlier and were sustained longer in the 2070s and 2080s than in the CTL. This can also be seen in the horizontal distributions shown in Fig. 2. Nevertheless, the suite of simulations offers no evidence that hurricanes powered by higher SST in future decades will cause overland wind speeds that are any higher than in contemporary storms. The weakest overland maximum surface wind speeds were simulated for the 2010s through the 2030s and the 2090s.

Fig. 9a shows time series of simulated precipitation rates averaged over the area within $180 \mathrm{~km}$ of the minimum surface pressure (storm center). The evolution of area-averaged precipitation rates parallels somewhat the evolution of area-averaged wind speed (Fig. 7). The CTL achieves one of the highest overall timeintegrated area-averaged precipitation accumulations, while the storms representing the 2080s and 2090s achieve noticeably lower precipitation rates. Here too, one can detect a negative decadal trend in storm intensity, in this case regarding precipitation rates. Fig. 9b shows time series of precipitation rates within $180 \mathrm{~km}$ of the storm center, averaged over land points. Individual time series represent the CTL, the average of the storms for the 2010s through the 2040s and the average of the storms for the 2050s through the 2080s. A time series of observations was also constructed from the averages of $3 \mathrm{~h}$ accumulations at all land stations

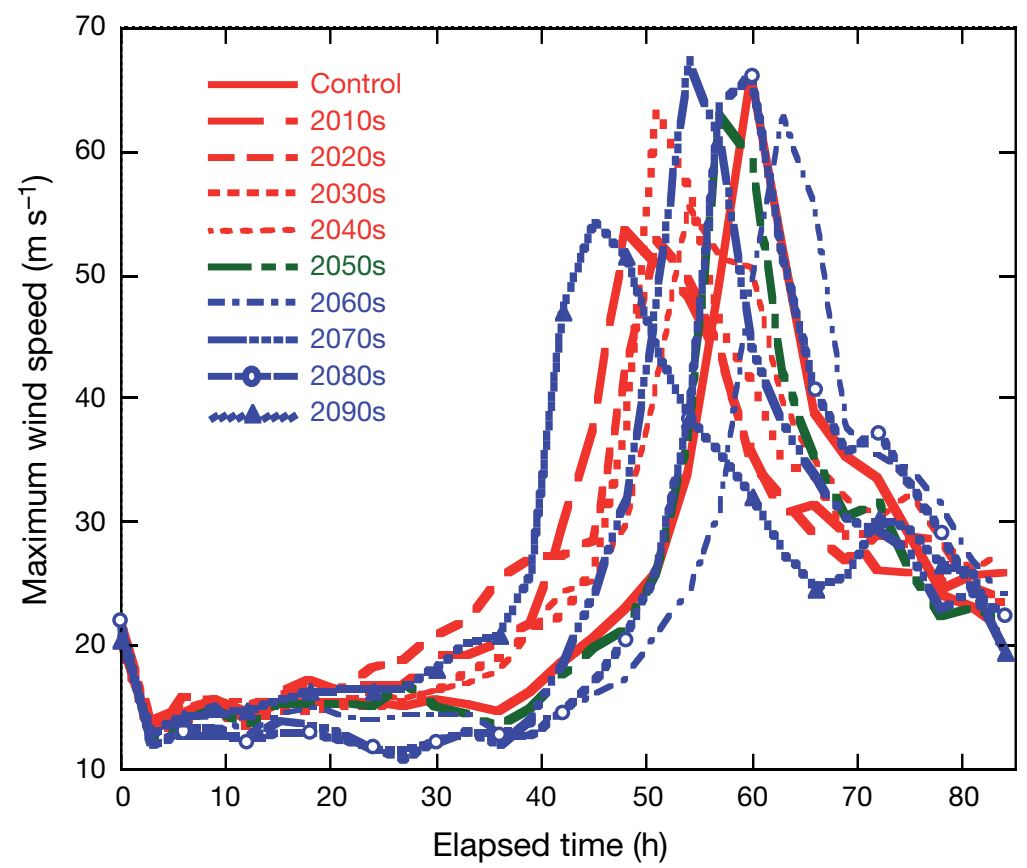

Fig. 8. Time series of maximum surface wind speed over a land point for each $3 \mathrm{~h}$ interval 


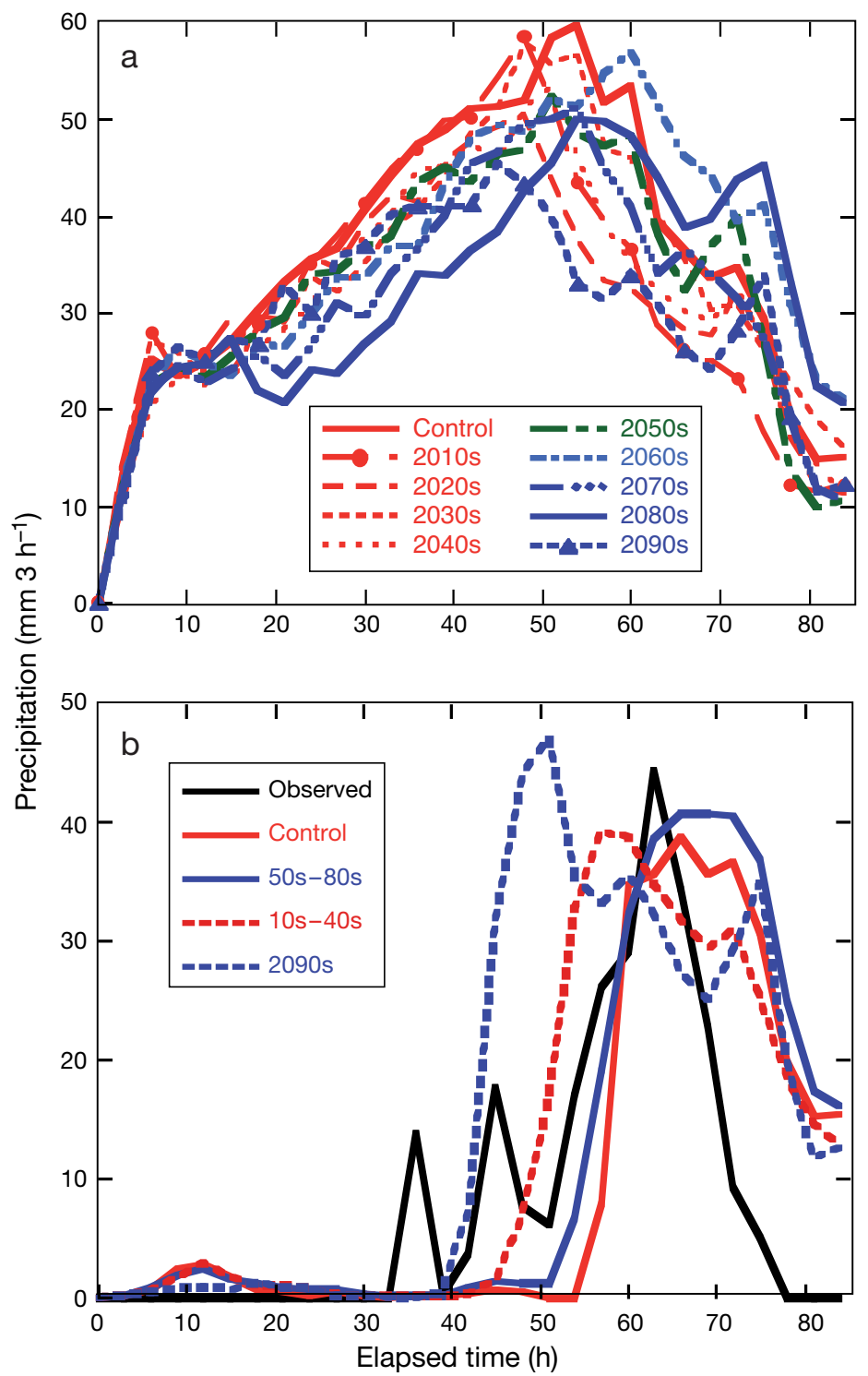

Fig. 9. (a) Time series of average precipitation rate within $180 \mathrm{~km}$ of storm center for each $3 \mathrm{~h}$ interval. (b) As in (a), but only for land points

within $180 \mathrm{~km}$ of New Orleans, Louisiana. Both the CTL and the station observations indicate the onset of heavy precipitation after $57 \mathrm{~h}$ of elapsed time. Peak rates for the CTL are also similar to the observed, although they persist somewhat longer. Storms for the 2010s through the 2040s feature onsets of heavy precipitation over land that were some $10 \mathrm{~h}$ earlier than for the CTL, reflecting their early approach to Florida. Precipitation rates for the simulated 2010s to 2040s storms are similar to the CTL. The time variation of precipitation rates over land for the 2050s through 2080s is closer to the CTL behavior in timing and magnitudes, featuring slightly earlier onset and slightly higher rates than the CTL. The onset of heavy overland precipitation for the 2090s storm is the earliest of all and this peak is the highest of all the simulations.

Fig. 10 shows vertical profiles of temperature anomalies relative to the CTL for the initial conditions of each decadal simulation, spatially averaged over an area bounded by $20-30^{\circ} \mathrm{N}, 80-95^{\circ} \mathrm{W}$. The troposphere for each decade is incrementally warmer than the previous one, but the warming is greatest at about $12 \mathrm{~km}$ altitude. Consequently, the atmospheric regime in which the storm develops is characterized by ever increasing vertical thermal stability from decade to decade. This trend explains the considerably lower wind speeds and rainfall rates associated with the predicted storms in the 2070s and 2080s. A control AOGCM simulation, run without greenhouse gas forcing, produces a $200 \mathrm{mb}$ temperature time series with a near zero trend between the 2000 s and the 2090 s, so the positive anomalies in Fig. 10 near $12 \mathrm{~km}$ altitude must be attributable to increasing concentrations of greenhouse gases and not to model drift.

\subsection{Impacts from random variability}

Multiple simulation ensembles are created to assess the impact of random noise on WRF simulations of Katrina-type storms. The evaluation here is based on ensembles for the control 2005 case and the climate change projections of the 2090s. All ensemble members are driven with the same LBC and SST as the original simulations, but each member starts from slightly altered initial conditions. Each of 8 additional simulations is begun from a unique initial condition at 00:00 h UT on 27 August, computed as follows:

$$
\begin{aligned}
& X_{1}=X_{00}+0.4\left(X_{18}-X_{00}\right) \\
& X_{2}=X_{00}+0.3\left(X_{18}-X_{00}\right) \\
& X_{3}=X_{00}+0.2\left(X_{18}-X_{00}\right) \\
& X_{4}=X_{00}+0.1\left(X_{18}-X_{00}\right) \\
& X_{5}=X_{00}+0.1\left(X_{06}-X_{00}\right) \\
& X_{6}=X_{00}+0.2\left(X_{06}-X_{00}\right) \\
& X_{7}=X_{00}+0.3\left(X_{06}-X_{00}\right) \\
& X_{8}=X_{00}+0.4\left(X_{06}-X_{00}\right)
\end{aligned}
$$

where $X_{1} \ldots X_{8}$ are the new variables for initial conditions, $X_{00}$ is the value of the variable from the GFS analysis at 00:00 h UT on 27 August, $X_{18}$ is the value of the variable from the GFS analysis for 18:00 h UT on 26 August and $X_{06}$ is the value of the variable from the GFS analysis for 06:00 h UT on 27 August. In summary, the initial conditions of 00:00 h UT are perturbed by anomalies that range from 40 to $10 \%$ of the differences between the original fields and fields from $6 \mathrm{~h}$ earlier and $6 \mathrm{~h}$ later. These perturbations can be thought of as 


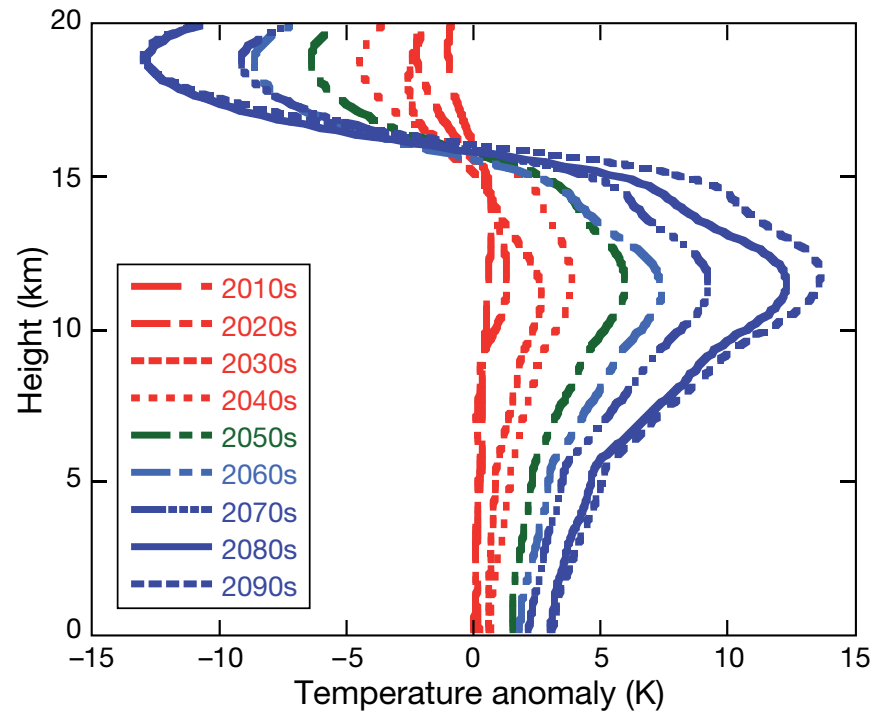

Fig. 10. Vertical profiles of temperature anomalies at 00:00 h UT on 27 August. Anomalies are relative to the control simulation and are averaged over the area $20-30^{\circ} \mathrm{N}, 80-95^{\circ} \mathrm{W}$

uncertainties in the specification of initial conditions, and the variability of the results therefore represents impacts of those uncertainties on the simulation experiments.

Storm tracks are minimally affected by the alternative initial conditions. Storm positions for both the 2005 control ensemble and the 2090s simulations, based on the minimum pressure at each $3 \mathrm{~h}$ interval, are mostly within $0.5^{\circ}$ of the original positions, and are often even closer. However, the ensembles do produce a range of minimum pressures and wind speeds. Fig. 11 shows the ensemble results for minimum sea-level pressure, average wind speed and maximum wind speed at 39 to $41 \mathrm{~h}$ elapsed time, the time interval at or close to the lowest central pressure. The range between ensemble members is larger for the 2090s simulations than for the control runs. However, all 2090s central pressures are higher and all average and maximum wind speeds are lower than for any of the 2005 simulations. Note also in Fig. 11b that higher average and maximum 2090s wind speeds are associated with the storms that register lower central pressures. The influence of perturbed initial conditions does not modify the finding that the 2090s version of Katrina is less intense than the 2005 representation, or that it tracks well to the east of the path obtained for the 2005 control simulation.

\subsection{Sensitivity experiments}

Simulations were made to evaluate the relative impacts of SST and LBC on the simulated 'future Katrina.' One experiment used initial conditions and LBC that were identical to the 2040s simulation reviewed above, combined with CTL SST, and a second experiment used CTL initial conditions and LBC combined with 2040s SST. Two more experiments similarly tested the relative impacts of 2090s SST and LBC. Fig. 12a compares the time series of minimum pressure for these 4 experiments to the CTL and the original 2040s and 2090s simulations. The storm's minimum surface pressure appears to be most sensitive to SST, with results indicating slightly more deepening for 2040s SST than in the CTL and a rather steep drop of about $40 \mathrm{mb}$ with 2090s SSTs, which are 2K warmer than CTL values over the entire hurricane track. In simulation experiments with a triply nested hurricane model, Shen et al. (2000) found that an SST increase of $2.5^{\circ} \mathrm{C}$ with no accompanying change in stability deepens the steady-state hurricane central pressure by about $26 \mathrm{mb}$. On the other hand, LBC containing future CCSs miti-

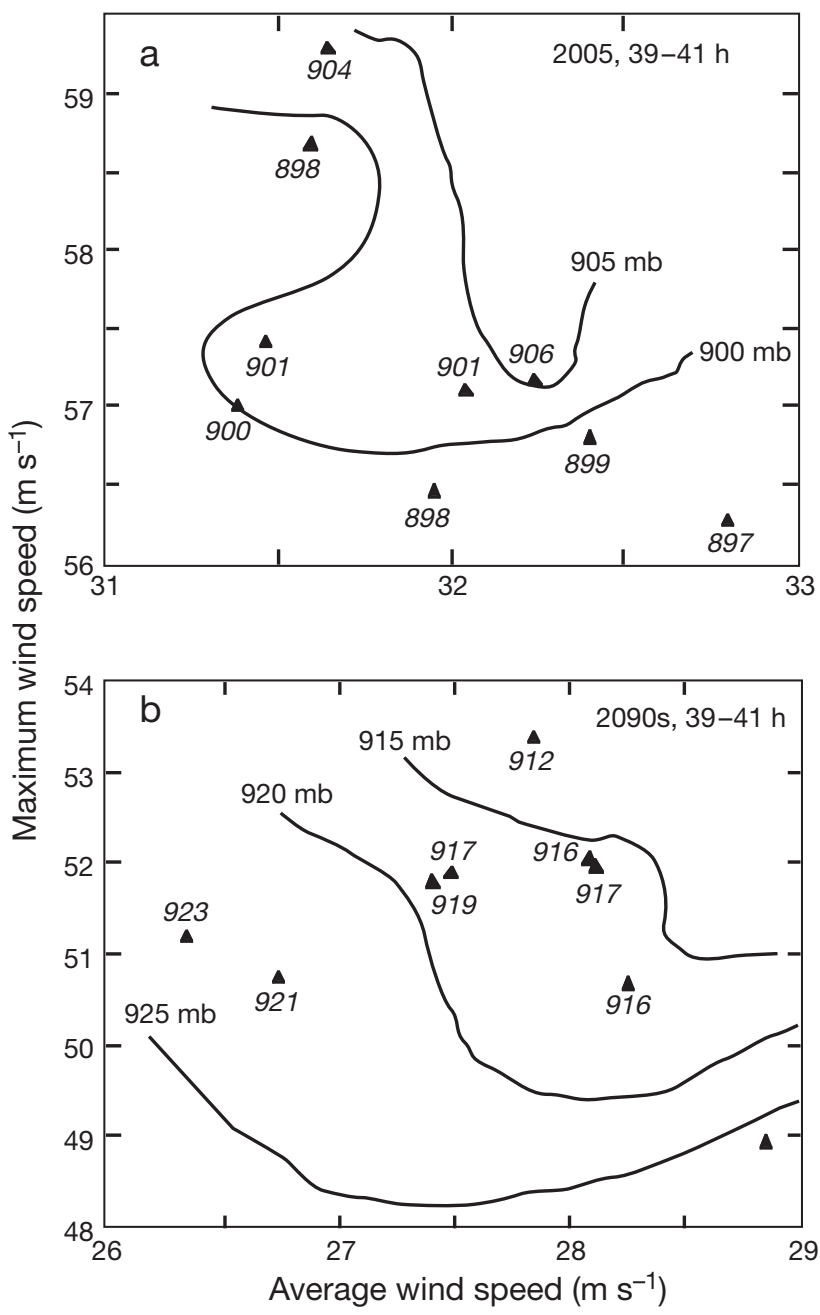

Fig. 11. Range of minimum sea-level pressure, average and maximum wind speed within $180 \mathrm{~km}$ of storm center after $39 \mathrm{~h}$ for ensembles of simulations from alternative initial conditions for (a) 2005 control and (b) 2090s 

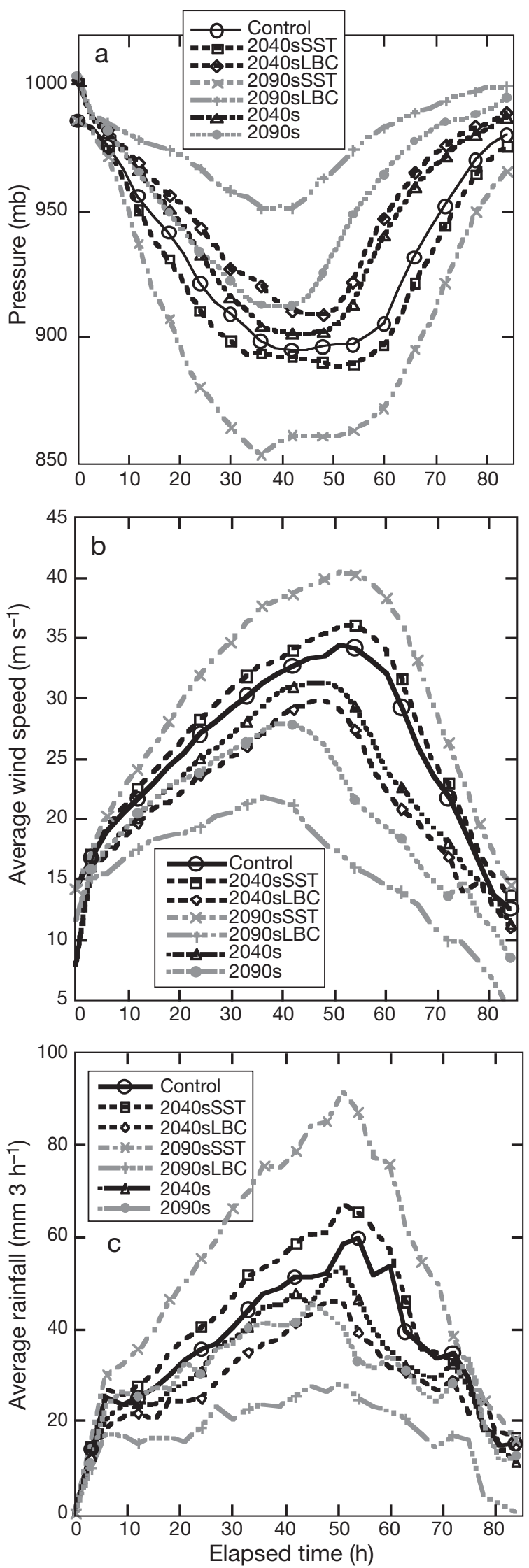

Fig. 12. (a) Time series of minimum surface pressure for the control simulation (CTL), 2040s, 2090s and 4 sensitivity experiments: 2040s lateral boundary conditions (LBC) with CTL sea surface temperature (SST), 2040s SST with CTL LBC, 2090s LBC with CTL SST, 2090s SST with CTL LBC. (b) As in (a), except for average wind speed within $180 \mathrm{~km}$ of storm center. (c) As in (b), except for precipitation rates

gate the deepening of the central pressure, so that the shallowest storm is simulated using 2090s LBC combined with 2005 (CTL) SST. The minimum central pressure for this case was some $50 \mathrm{mb}$ higher than simulated in the CTL. The relative impacts of SST and LBC for the 2040s were considerably smaller than for the 2090s, but still in the same sense. The evolution of area-averaged wind speed and precipitation rates (within $180 \mathrm{~km}$ of storm center) parallel the results for minimum pressure (Fig. 12b,c). The highest peaks in area-averaged wind speed and precipitation are associated with 2090s SST and the lowest with 2090s LBC. The inhibiting influences of LBC representing future atmospheres is likely related to trends of increased vertical thermal stability, as depicted in Fig. 10 and discussed in Section 3.2. Shen et al. (2000) and Knutson \& Tuleya (2004) also concluded that increases in upper tropospheric temperatures associated with $\mathrm{CO}_{2}$ induced warming exert a mitigating effect that opposes hurricane intensification from increasing SST. In fact, in simulation experiments with a triply nested hurricane model, Shen et al. (2000) found that a $1.5^{\circ} \mathrm{C}$ increase in SST can be compensated by the concomitant effect of a positive upper-tropospheric temperature anomaly of about 3 to $4^{\circ} \mathrm{C}$, resulting in little change of minimum pressure. Note also that impacts on wind speed create a positive feedback, in that simulations with increased (slower) surface wind speeds also experience greater (lower) upward latent heat fluxes, making more (less) energy available for the developing storm system.

\section{CONCLUSIONS}

Simulation experiments reported by Knutson \& Tuleya (2004) predicted increases in both tropical storm intensity and near-storm precipitation rates throughout the 21st century as a consequence of warming from positive trends in greenhouse gases. Emanuel et al. (2008) found indications that Atlantic hurricane intensity will increase into the 22nd century. The present study examines the behavior of a single storm and investigates, via 30 alternative WRF regional simulations on a grid with $9 \mathrm{~km}$ spacing, how future atmospheric boundary conditions and future SST might impact its evolution. Conclusions must be 
interpreted cautiously since the $9 \mathrm{~km}$ grid spacing does not resolve the highest actual gradients, maximum winds or convergence extremes and, moreover, simulations used prescribed SST rather than an interactive ocean. In addition, projections are based on one particular AOGCM and are therefore subject to that model's biases. Results suggest that, during the latter part of the 21st century, the radius of strong winds in a Katrina-like storm will decrease, but the pressure minimum will be more extreme and maximum wind speeds will be higher and more prolonged after landfall.

The CTL is driven by GFS data representing the observed atmospheric conditions from 27 to 30 August 2005. Adding a signal derived from an AOGCM A2 climate change projection to $4 \times$ daily GFS data from the original 2005 event creates LBCs for climate change simulations. The resulting atmospheric conditions in which the developing storm was imbedded reflect incremental tropospheric warming in each subsequent decade of the 21st century. The CCS in the boundary conditions for each WRF simulation is based on AOGCM climate projections for 10 consecutive summers, so it is more representative of the A2 scenario forcing than forcing for any individual summer would be. Since the decadal warming is most pronounced at about $12 \mathrm{~km}$ altitude, the vertical thermal stability increases from decade to decade. This increase is likely responsible for some of the initial inhibitions on storm development detected for simulations representing later decades of the 21st century; however, decadal increases in SST mitigate these inhibitions.

Compared with the CTL, the simulations for the 2050s through the 2080s delay the deepening of the storm's central pressure by 10 to $20 \mathrm{~h}$. The general trend of decadal increases in SST parallels decadal decreases in storms' minimum central pressure. High winds are confined to a smaller diameter in the simulations representing 2070s and 2080s storms than in the CTL, but these versions of Katrina make landfall about $6 \mathrm{~h}$ earlier and preserve a ring of high wind speeds that disappeared in the CTL. They feature the lowest central pressures of all experiments and maximum wind speeds over land that exceeded $60 \mathrm{~m} \mathrm{~s}^{-1}$ some 3 to $6 \mathrm{~h}$ earlier than the CTL, sustained over a period approximately twice as long.

Zonal steering currents are stronger in the simulations representing the first half of the 21st century, so that storm trajectories are more easterly than for the CTL. Weakened zonal steering currents for the 2050s through the 2080s are consistent with lower meridional temperature gradients in the lower troposphere along the Gulf coast, prompted by higher temperatures over the Lower Mississippi Valley.
The behavior of the storm in the 2090s simulation is quite anomalous in many respects, and this behavior is common to all 9 realizations of the 2090s ensemble. The track is east of the CTL, similar to the simulations for the earlier decades. The central pressure of the 2090s storm does not deepen as much as for other storms in the latter decades and is therefore inconsistent with some of the warmest SSTs. Its lowest central pressure occurs rather early, after only $39 \mathrm{~h}$, compared to $45 \mathrm{~h}$ for the CTL. Positive zonal wind anomalies in the upper troposphere for the 2090s are more than twice the strength computed for the next strongest case, suggesting an El Niño-like regime, often characterized by strong westerly jet streams over the Gulf coast. Westerly wind anomalies in the lower troposphere steer the 2090s storm to an early landfall over the Florida panhandle, undoubtedly interrupting pressure falls and accounting for its rather shallow and premature minimum pressure. In addition, the CCS imposed for the 2090s creates an environment with the highest vertical thermal stability of all the decades and a large positive wind shear, conditions that also inhibit storm development. Eight additional 2090s simulations from altered initial conditions, but forced by the same LBC and SST, fail to suggest any variability in storm track, but do feature a range of wind speeds that is about $12 \%$ of the storm's area average.

Sensitivity experiments here suggest that the warmer atmospheric environment in which future storms are embedded will inhibit storm intensification, even while the future (warmer) SSTs contribute to more intense systems. This conclusion agrees with the results of previous modeling studies that tested the impact of decadal warming on simulated hurricane intensity and precipitation (Shen et al. 2000, Knutson \& Tuleya 2004). Thus, the extremely low minimum pressures for 2070s and 2080s storms are apparently caused by the very high SSTs the storms encountered over the Gulf of Mexico, while their relatively small diameters may reflect the high vertical thermal stability of the late decades. Our results, using real boundary conditions modified by a CCS, suggest that the danger to coastal locations from the high winds of severe hurricanes could increase toward the end of the coming 9 decades.

Acknowledgements. This research was partially supported by the National Aeronautics and Space Administration (NASA) Climate Variability and Climate Change Programs. L.M.D. was partially supported by National Science Foundation Grant ATM-0652518 and NASA Grant NNX07AI93G. The authors acknowledge the preliminary analysis of results made by R. Levine. The Ring Family Foundation supports computing facilities at the Hebrew University of Jerusalem, where simulations were run. 


\section{LITERATURE CITED}

Emanuel K, Sundararajan R, Williams J (2008) Hurricanes and global warming. Bull Am Meteorol Soc 89:347-367

Giorgi F, Marinucci M (1996) An investigation of the sensitivity of simulated precipitation to model resolution and its implications for climate studies. Mon Weather Rev 124: 148-156

Giorgi F, Brodeur C, Bates G (1994) Regional climate change scenarios over the United States produced with a nested regional climate model: spatial and seasonal characteristics. J Clim 7:375-399

Han J, Roads J (2004) U.S. climate sensitivity simulated with the NCEP Regional Spectral Model. Clim Change 62: $115-154$

IPCC (2007) Climate change 2007: synthesis report. Contribution of Working Groups I, II and III to the Fourth Assessment Report of the Intergovernmental Panel on Climate Change. IPCC, Geneva

Knutson T, Tuleya R (2004) Impact of $\mathrm{CO}_{2}$-induced warming on simulated hurricane intensity and precipitation: sensitivity to the choice of climate model and consecutive parameterization. J Clim 17:3477-3495

Knutson T, Sirutis J, Garner S, Held I, Tuleya R (2007) Simulation of the recent multi-decadal increase of Atlantic hurricane activity using an 18-km-grid regional model. Bull Am Meteorol Soc 88:1549-1565

Leung L, Qian Y, Bian X (2003) Hydroclimate of the western United States based on observations and regional climate simulations of 1981-2000. I. seasonal statistics. J Clim 16:1892-1911

Leung L, Qian Y, Bian X, Washington W, Han J, Roads J (2004) Mid-century ensemble regional climate change scenarios for the western United States. Clim Change 62: 75-113

Lynn B, Healy R, Druyan L (2007) An analysis of the potential for extreme temperature change based on observations and model simulations. J Clim 20:1539-1554

Editorial responsibility: Bryson Bates, Wembley, Western Australia
Lynn B, Healy R, Druyan L (2009) Quantifying the sensitivity of simulated climate change to model configuration. Clim Change 92:275-298

> Mass C, Ovens D, Westrick K, Colle B (2002) Does increasing horizontal resolution produce better forecasts? The results of two years of real-time numerical weather prediction over the Pacific Northwest. Bull Am Meteorol Soc 83: 407-430

Misra V, Kanamitsu M (2004) Anomaly nesting: a methodology to downscale seasonal climate simulations from AGCMs. J Clim 17:3249-3262

> Nobre P, Moura A, Sun L (2001) Dynamical downscaling of seasonal climate prediction over Nordeste Brazil with ECHAM3 and NCEP's regional spectral models at IRI. Bull Am Meteorol Soc 82:2787-2796

Pielke R Jr, Gratz J, Landsea CW, Collins D, Saunders M, Musulin R (2008) Normalized hurricane damages in the United States: 1900-2005. Nat Hazards Rev 9:29-42

Rangwala I, Miller JR, Russell GL, Xu M (2006) Analysis of global climate model experiments to elucidate past and future changes in surface insolation and warming in China. Geophys Res Lett 33:L20709 doi:10.1029/2006 GL027778

Rojas M, Seth A (2003) Simulation and sensitivity in a nested modeling system for South America. II. GCM boundary forcing. J Clim 16:2454-2471

Russell GL, Miller JR, Rind D (1995) A coupled atmosphereocean model for transient climate change studies. AtmosOcean 33:683-730

Shen W, Tuleya RE, Ginis I (2000) A sensitivity study of the thermodynamic environment on GFDL model hurricane intensity: implications for global warming. J Clim 13: 109-121

Skamarock WC, Klemp JB, Dudhia J, Gill DO, Barker DM, Wang W, Powers JG (2005) A description of the advanced research WRF version 2. NCAR Technical Note NCAR/ TN-468+STR, National Center for Atmospheric Research (NCAR), Boulder, CO

Submitted: August 13, 2008; Accepted: April 24, 2009 Proofs received from author(s): June 8, 2009 